\title{
Legal Aspects of Ensuring Security When using Personal Electric Transport in Russia and Abroad
}

\author{
Iroshnikov Denis Vladimirovich ${ }^{1}$, Nemova Ninel Yurievna ${ }^{2}$, Shevchenko Kirill Vladimirovich ${ }^{2} \&$ Utkin Nikolay \\ Ivanovich $^{2}$ \\ ${ }^{1}$ Russian University of Transport, Russia \\ ${ }^{2}$ Saint Petersburg University of State Fire Service of Emercom of Russia, Russia \\ Correspondence: Iroshnikov Denis Vladimirovich, Russian University of Transport, Russia. E-mail: \\ dv-iroshnikov@mail.ru
}

Received: March 14, 2020

Accepted: April 13, $2020 \quad$ Online Published: May 27, 2020

doi:10.5539/jpl.v13n2p235

URL: https://doi.org/10.5539/jpl.v13n2p235

\begin{abstract}
Transport plays a fundamental role in the life of society. The fast pace of life, especially in metropolises and cities, imposes new requirements towards human mobility. With the development of technologies unprecedented transport solutions have become popular. Specifically, in different countries personal electric transport (segway, self-balancing scooter, electric scooter, unicycle etc.) has assumed widespread use. The number of such vehicles is constantly growing. As known, any means of transport presents a hazard. That is why it is important to pay special attention to personal security when using this kind of transport.

Based on the analysis of the current Russian and foreign legislations, case materials, scientific sources, the article investigates legal problems of ensuring personal security when using personal electric vehicles. In this respect, the authors consider the issues of ensuring safety of both a driver and a pedestrian, and third parties as well.

The conducted legal research has allowed us to make a conclusion on the necessity of improving legislation in the sphere of using personal electric transport. In the authors' opinion, one should start with statutory recognition of the very notion of "personal electric transport", which must include characteristic features that allow to differentiate between this particular kind of transport and other vehicles. Nothing but comprehensive legal regulation based on a detailed analysis of possible risks, can prevent personal security hazards when using personal electric transport.
\end{abstract}

Keywords: road safety, traffic regulations, pedestrian, personal electric transport, electric scooter, Segway, self-balancing scooter, unicycle

\section{Introduction}

Nowadays, such means of transport as segway, self-balancing scooter, electric scooter, unicycle and others are confidently coming into the Russian and global markets. The use of this kind of transport, especially in large cities and metropolises, is substantially growing by the day.

This mainstream use of personal electric transport in cities (with traffic mostly on the pavements) raises an acute issue of safety of road users including pedestrians in particular. There have already been registered a number of pedestrian knockdown accidents resulting in harm to health of various severity degree.

It seems to us that within the framework of ensuring personal security when using personal electric transport, two aspects can be singled out:

- $\quad$ ensuring safety of an individual who drives such vehicles;

- $\quad$ ensuring safety of pedestrians and other road users as well as third parties (not road users) who can be hurt from the use of this kind of vehicles.

At present the legal status of personal electric transport is defined quite ambiguously in Russia. In current traffic regulations these vehicles are not referred to any particular kind of transport intentionally.

The legal definition assigned in Traffic regulations contains the following phrase: "individuals using rollerblades, scooters, and other similar means of transport are treated as pedestrians. It gives some law enforcement bodies 
and scientists grounds for classifying drivers of this transport as pedestrians.

But in real life it is not so clear-cut. Analysis of relevant judicial practice shows that definition of the legal status of a person who drives such means of transport is influenced by technical characteristics of a vehicle and electric motor power in particular. Thus, under certain conditions electric scooter can be regarded as moped (with the 0.25 kilowatt engine). However, Russian judicial practice is not always unambiguous in this respect.

In this context, the very notion of moped contained in Traffic regulations of the Russian Federation implies "two - or the three-wheeled vehicle". It means that such type of electric transport as "unicycle" does not meet the given definition in terms of the number of wheels.

If we assume electric scooters with electric motor power of more than 0.25 kilowatt to be mopeds, individuals using the given means of transport will be obligated according to the Traffic regulations to comply with right-hand driving on the roadway or along the cycle path. Consequently, driving such vehicles on the pavement or sidewalks is forbidden.

In this respect, we suppose that common sense prevents the driver of electric scooter from moving along the edge of the carriageway. In our view, small wheel diameter, shallow tread pattern, light weight of electric scooter do not make it possible to operate such a vehicle safely on public roads. Thus, oil spills, mud and slush by the side of the road, stones and other road debris on the carriageway, pockets and road roughness can cause roll over of electric scooter and collision of other vehicles at the driver. This law-enforcement position will have an impact on safety of the drivers of electric scooters and similar means of transport.

However, driving these vehicles on the pavements causes the opposite problem. Nowadays, residents in Moscow, St. Petersburg and other large Russian cities have to witness cases of driving personal electric transport in the way that cannot ensure pedestrian safety. These cases are underage driving and drink-driving, driving at speed limits in a high-density crowd (including children) on pavements, in yards, parks and square gardens. With this background, pedestrian knockdown accidents are conceivable and the issue of safety of other road users arises.

Nowadays, these problems must be addressed as promptly as possible by legal arrangements.

\section{Methods}

Systematic approach provided a detailed study of the system of legal regulation and enforcement of law as applied to individuals that use personal electric transport. Comparative law method allowed us to conduct comparative analysis of Russian and foreign legislations aimed at borrowing foreign expertise of legal regulation. Apart from the given methods there were also applied methods of analysis, synthesis, induction, deduction, and the method of scientific modeling which allowed to consider the model of law enforcement safety measures when using personal electric transport.

An important methodological aspect in examining the issues of personal and public security is the necessity to implement the pragmatic function of science, since security provision presumes well-timed actions on detecting, analyzing and assessing security threats. Within the framework of the given investigation the authors found out a number of loopholes in the current legislation, which can become a security threat towards road users.

The distinctive feature of methodological approach applied in the article is combination of the study of current statutory provisions, other researchers' standpoint to the matter, and practical application of legal norms by judicial authorities. On the basis of this investigation, the given methodological approach has allowed to summarize existing problems and suggest legal developments in the current Russian legislation.

\section{Results and Discussion}

Different research papers can provide results of statistical investigations of injuries got while driving segway and other similar means of transport. Some foreign scientists came to the conclusion that severity of injury of a number of patients traumatized when driving self-balancing personal transport is significant. Other scholars note that similarly with pedestrians and cyclists, scooter drivers are considered to be vulnerable road users and, as expected, will be seriously injured in road accidents. In another view, it is necessary to make sure that transport rental workers will provide laymen with adequate safety instructions before they first ride a segway. According to the research results of Japanese scientists concerning possible injuries of pedestrians knocked down by personal electric transport, experiments based on specific aspects of human perception, have shown that pedestrians display high sensitivity to objects speeding ahead and low sensibility to objects speeding from the back.

The authors of the research paper titled as "Diversity of "Pedestrians on Wheels". New Challenges for Cities in 21 st Century" note that rapid spread and growing tendency of new devices of pedestrian mobility in cities 
together with weak legal framework in the view of regulation cause certain problems. In the authors' opinion, electric mobility vehicles endow their user with intermediate status between pedestrians and automobiles.

Researchers suggested classifying the given vehicles on the basis of their speed limit, distance, weight and existing sharp edges which can injure people in case of an accident. Depending on this classification it is planned to determine designated area for their use (pavement, cycle lane, or road). Concluding the article the authors suggest legal regulation of training electric vehicle users including getting driving license to operate some types of this transport. It is also suggested to regulate the use of this transport depending on different types of such vehicles as well as designated area of their driving (dedicated lane, carriageway or pavement) and speed limits.

It is necessary to pay attention to the research report published in 2017 titled as "Regulations and safety for electric bicycles and other low-powered vehicles" elaborated by ViaStrada Limited Company which was hired by New Zealand transport agency to conduct this research. The document consists of 182 pages including charts, tables, schemes and diagrams.

57 models of electric scooters and similar vehicles of famous brands were examined including their speed limit and engine power. According to the presented table, most models of such vehicles submitted in research have engine power of more than 250W. It means that in the view of the current Russian legislation and its practical application, they can be regarded as mopeds.

Concerning pedestrian safety, committee of experts makes a conclusion on new considerations in the design of pavements and streets in order to minimize injuries resulted from a tip over, obstructions or poor road surface, conflicts with pedestrians or approach roads.

Issues on legal regulation of personal electric transport in foreign countries are of great interest.

In the USA legislation on the use of personal electric transport has already started to develop since the beginning of 2000s. So, by October 2003, 45 states and the District of Columbia have adopted legislation which permitted the use of the given transport on pavements. At the same time lots of states expanded designated areas enclosing motorways.

However, from state to state operation requirements of personal electric transport vary in the following way:

- granting pedestrian rights and responsibilities to transport users (Connecticut, New York, Montana and others) or cyclist rights and responsibilities in accordance with permitted operational infrastructure (New Jersey, New Mexico, Utah and others);

- obligation to give way to pedestrians, to sound horn overtaking pedestrians and to ride at a lower speed on pavements (North Carolina, New Hampshire, New Mexico and others);

- obligation to have extra equipment such as lights and reflectors in the dark (New Hampshire, New Mexico, Virginia and others);

- obligation of adolescent users to wear helmets (Utah, Pennsylvania, Georgia and others) and the same requirement regardless of age in New Jersey;

- minimum age requirements (Utah, Virginia, Missouri and others).

The legal definition of the notion "low-speed electric scooter" is noticed in the United States Code (Paragraph 2085, chapter 47 "Consumer Product Safety") and means a two- or three-wheeled vehicle with fully operable pedals and an electric motor of less than 750 watts ( 1 h.p.), whose maximum speed on a paved level surface, when powered solely by such a motor while ridden by an operator who weighs 170 pounds (about $77 \mathrm{~kg}$ ), is less than $20 \mathrm{mph}$ (about $32 \mathrm{~km} / \mathrm{h}$ ). It should be noted that only electric bicycle (because of having available pedals) fits the given definition.

According to recommendations by the Active Mobility Advisory Panel on rules and code of conduct for cycling and the use of personal mobility devices submitted to coordinating minister for infrastructure, and minister for transport of Singapore, on pavements it is allowable to use bicycles and personal mobility devices, but at speed limit of $15 \mathrm{~km} / \mathrm{h}$. On bicycle lanes it is permitted to use a bicycle, personal mobility devices and electric bicycles but at speed limit of $25 \mathrm{~km} / \mathrm{h}$. Along with this, only bicycles and electric bicycles can be ridden on roads. Thus, riding electric scooter on the road is not recommended by the authors of the document.

In explanatory memorandum to Directive of the European Parliament on amending Directives relating to insurance against civil liability in respect of the use of motor vehicles, and the enforcement of the obligation to ensure against such liability, it is said that member states of the European Union can release such vehicles from civil liability insurance if they consider it is necessary. Thus, European Union states independently decide the 
issue of the necessity of civil liability insurance of individual electric transport users.

According to Regulation (EU) No 168/2013 of the European Parliament and of the Council of 15 January 2013 on the approval and market surveillance of two- or three-wheel vehicles and quadricycles, it doesn't apply to the vehicles not equipped with at least one seating position. So we can make a firm conclusion that electric scooters without seats cannot be regarded as a vehicle in EU states.

Comparative law analysis of foreign legal acts and other official documents has shown that the worldwide trend aimed at extensive use of personal electric transport, makes states take measures concerning legal regulation of using such vehicles. At that point, different countries address the given issue in different ways and the worldwide practice has not been applied yet.

The issue of personal electric transport rentals through smartphone apps should be specifically examined. Electric scooter rental appeared in Moscow in 2018 and nowadays their fleet is growing. According to the Russian legislation the owner of electric scooter rental agency by his own efforts and expenses gives his clients' notice of requirements of traffic regulations of the Russian Federation, guidelines of using rental centers and scooters established by the owner. The rentaller also informs clients on safety measures when operating scooters and safety precautions for road use. Thus, information that this or that hired scooter is treated as a moped according to current Russian legislation and that driving license is necessary must be provided to a client by rental agency.

However, in real practice it may appear to be far otherwise. In mobile apps this information can be placed in such a way that it will not draw the lessee's attention. As a result, he will be honestly misjudged with the fact that he is driving a moped and appears to be potential administrative offender. Such cases are affirmed through analysis of judicial practice. For instance, the applicant, appealing against the magistrate judge's decision on instituting administrative action for the offence committed when using electric scooter, relied on the fact that on the stage of contraction he had not been informed that the given vehicle came under the category of a moped. However, the court considered it to be a vicious argument as the driver in view of traffic regulation provisions, should have ascertained the availability of a special driving license and fulfilled legal responsibilities. This example of judicial practice reveals the real problem which the drivers of electric scooters in Russia may face.

In terms of comparative analysis we can consider the issues of short rent of scooters in Helsinki. At present, this service is quite widespread in the capital of Finland and its proportions far outweigh similar supply in Moscow.

Upon the information of one of the largest firms providing such rental service, lessees of scooters must be of legal age according to manufactories manual. The company control's its client's age through his or her payment card as well. Nowadays, the necessity of scanning lessee's driving license before driving electric scooter is being considered. But such practice has not come into effect yet.

In order to grasp the current situation in Russia a comprehensive scientific analysis of the common judicial practice was held on the given issue. The analysis involves administrative judgments in Russia in a period from January 2019 to March 2020. The line of investigation was determined on the basis that until 2019 there were not any lawsuits of this kind in Russia.

The findings of investigation have shown that in Russia the existing judicial practice is quite contradictive.

In one of lawsuits of District Court in Moscow in the case of pedestrian collision declared an electric scooter to be a vehicle and the person who was using it a driver of the vehicle and thus, instituted administrative action against this person. However, the issue on technical features of electric scooter and its engine power was not addressed.

The other District Court in Moscow declared that the person, who was using electric scooter which technical features matched the notion of "moped", was a driver, that is a proper party of administrative liability.

A special interest for the given research represents the legal resolution of the Supreme Court of the Udmurt Republic, which deals with a dispute between a person and a judge. The person was driving electric scooter with an electric motor of 0,25 kilo watt which technical features (from his viewpoint) do not allow to regard it as a moped. The judge (whose decision was appealed) considered that the given vehicle can be regarded a moped according to the Traffic regulations. In this case electric motor power is the issue of debate as it is on the line between electric scooter and moped.

However, the judicial practice contains a markedly different position. For example, in the appeal judgment of the District Court in Kemerovo the judges came to the conclusion that, following the statutory provisions of the Russian legislation, persons using roller blades, scooters and other similar means of transport (in conjunction with performance characteristics this category may include segways, self-balancing scooters, unicycles, electric 
scooters) are considered to be pedestrians, that is, according to legislation of the Russian Federation the mentioned facilities are not treated as "means of transport". So, the judge has entirely excluded electric scooters from the concept of "means of transport" taking no account of engine power.

A separate acute problem, which is not regulated by the current legislation is crossing the road on an electric scooter. According to Russian legislation one can cross the road in roller blades or by scooter and other similar vehicles (in these cases a person is treated as a pedestrian). Moreover, a cyclist is forbidden to use pedestrian crossing. It means that following Traffic regulations he must get off the bicycle and cross the road on foot.

For electric scooter the procedure of crossing the road is not regulated by Russian legislation. Analysis of judicial practice allowed us to find out contradictions. For instance, in one of lawsuits the court ruled that a person driving an electric scooter when crossing the road cannot be treated as a pedestrian.

Moreover, the view set out in another judgment stands in direct contradiction with the above mentioned position: "The given arguments that the complainant was crossing the road on electric scooter is not the reason for the remission of administrative liability, since under the Traffic regulations a scooter is not treated as a vehicle". Similar view is traced in other judicial acts.

Thus, the conducted research of Russian judicial practice gives us grounds to make a conclusion that the there is no single approach to the legal status of individuals using personal electric transport. Court decisions are in direct contradictions with each other. In this respect, it is considered useful to address this problem by improving legislation.

\section{Summary}

In this respect it seems appropriate to propose the following amendments in the current Russian legislation and, in this framework, regulate social relations concerned with the use of personal electric transport, namely:

1) To affirm a unifying concept "personal electric transport" for such kinds of vehicles as electric scooter, segway, self-balancing scooter, unicycle and others. It seems to us that the given notion will, on the one hand, generalize different kinds of electric transport (segway, unicycle, electric scooter) and, on the other hand, differentiate them from other means of transport (automobiles, motorcycles and others).

2) To formalize classification of the given means of transport depending on their type, electric motor power, speed limit and other bases. This classification will make it possible to assimilate by the legal status some vehicles to bicycles, mopeds, and others to push scooters or rollerblades (that is not to admit them as vehicles). And the driver of this transport will be assimilated to a pedestrian.

3) To determine on the legal basis minimum age for driving personal electric transport depending on its type.

4) To determine designated area of use depending on the type of personal electric transport (pavements, cycle lanes, parks, square gardens and others). It seems to us that we must not allow to use them on public roads in order to ensure safety of electric vehicle drivers. Also, it is advisable to introduce maximum vehicle speed limit (for example, driving on the pavement).

5) To formalize obligations for producers and suppliers of personal electric transport to label a vehicle with engine power and (or) its type, and probably to introduce requirements to minimal vehicle configuration (lights, reflectors etc).

6) To make provision for various kinds of legal liability at different stages of buying, renting and operating personal electric transport beginning with responsibility of producers and suppliers of these vehicles, rental agencies and ending with responsibility of individuals driving such transportation devices that present hazards.

7) For the drivers of certain categories of personal electric transport it is possible to make provision for voluntary civil liability insurance by introducing amendments into insurance legislation.

\section{Conclusions}

Such legislative amendments are meant to become the legal basis of ensuring personal security when using personal electric transport of not only drivers but pedestrians and other road users, as well as third parties. Only complex legal regulation based on detailed analysis of possible risks, can prevent hazards to personal security when using personal electric transport.

\section{References}

Ayupova, G. S., \& Makeyeva, I. S. (2019). The Peculiarities of Classification of Road Traffic Rules Violations and Operation of Transport Vehicles Determined by Elements of a Subject-Matter. Criminal law, (1), 7. 
Boniface, K., PatMcKay, M., Lucas, R., Shaffer, A., \& Sikka, N. (2011). Serious Injuries Related to the Segway Personal Transporter: A Case Series. Annals of Emergency Medicine, 57(4), 370. https://doi.org/10.1016/j.annemergmed.2010.06.551

Delfín, J., Yolanda, de la F., \& Jesús, H.-G. (2018). Diversity of "Pedestrians on Wheels", New Challenges for Cities in 21st Century. Studies in Health Technology and Informatics, 256, 360.

Judgement of Chamovnicheskian district court of Moscow from April 4, 2019 № 12-542/19. SPS «ConsultantPlus». Retrieved from http://www.consultant.ru

Lieswyn, J., Fowler, M., Koorey, G., Wilke, A., \& Crimp, S. (2017). Regulations and safety for electric bicycles and other low-powered vehicles. NZ Transport Agency research report 621. New Zeland.

Proposal for a Directive of the European parliament and of the council amending Directive 2009/103/EC of the European Parliament and the Council of 16 September 2009 relating to insurance against civil liability in respect of the use of motor vehicles, and the enforcement of the obligation to ensure against such liability. Brussels, 24.05.2018 COM (2018). 336 final. 2018/0168 (COD). Retrieved from https://eur-lex.europa.eu/LexUriServ/LexUriServ.do?uri=COM:2011:0008:FIN:EN:PDF

Recommendations on Rules and Code of Conduct for Cycling and The Use of Personal Mobility Devices. Recommendations by the Active Mobility Advisory Panel Submitted to Coordinating Minister for Infrastructure, and Minister for Transport, Mr Khaw Boon Wan on 17 March 2016. Retrieved from https://www.lta.gov.sg/data/apps/news/press/2016/20160317_AMAPPanelReport\%28final\%29.pdf

Regulation (EU) No 168/2013 Of the European Parliament and of the Council of 15 January 2013 on the approval and market surveillance of two- or three-wheel vehicles and quadricycles (Text with EEA relevance). Retrieved from https://eur-lex.europa.eu/legal-content/EN/TXT/PDF/?uri=CELEX:32013R0168

Roider, D., Busch, C., Spitaler, R., \& Hertz, H. (2016). Segway related injuries in Vienna: report from the Lorenz Böhler Trauma Centre. European Journal of Trauma and Emergency Surgery, 42(2), 203-205. https://doi.org/10.1007/s00068-015-0532-x

Shaheen, S. A., Rodier, C. J., \& Eaken, A. M. (2005). Improving California's Bay Area Rapid Transit District Connectivity and Access with Segway Human Transporter and Other Low-Speed Mobility Devices. Transportation Research Record: Journal of the Transportation Research Board, 1927(1), 192. https://doi.org/10.1177/0361198105192700122

U.S. Code. Title 15. Commerce and trade Chapter 47. Consumer product safety. Section 2085. Low-speed electric bicycles. Retrieved from https://www.law.cornell.edu/uscode/text/15/2085

Xua, J., Shang, S., Yu, G. Z., Qi, H. S., Wang, Y. P., \& Xu, S. C. (2016, February). Are electric self-balancing scooters safe in vehicle crash accidents? Accident Analysis \& Prevention, 87, 115-116. https://doi.org/10.1016/j.aap.2015.10.022

Yu, H., Charitha, D., Miho, I.-A., \& Hiroaki, N. (2018). Modeling pedestrians' subjective danger perception toward personal mobility vehicles. Transportation Research Part F: Traffic Psychology and Behaviour, 56, 266. https://doi.org/10.1016/j.trf.2018.04.016

\section{Copyrights}

Copyright for this article is retained by the author(s), with first publication rights granted to the journal.

This is an open-access article distributed under the terms and conditions of the Creative Commons Attribution license (http://creativecommons.org/licenses/by/4.0/). 